a polity, a public with a sense of purpose and power. Citing Bergin (2011) he argues that priority needs to be given to

... preventing radical disengagement ... and to promote political attention and activity among those segments of the population most likely to suffer when disengaged. (p. 185)

Perrin's book is a useful reminder that democracy can only survive when citizens are fully involved._-Dr Philip Cass

\title{
Media representations of global cities
}

Media and the City, by Myria Georgiou. Cambridge, Polity Press, 2013, 184pp. ISBN: 9780-7456-4855-2

N Media and the City Myria Georgiou claims 'global cities' such as London aren't just examples of diversity and difference, but are also responsible for creating those very qualities. However, it's never entirely clear how this is actually achieved.

She suggests the way we feel about urban centres is influenced by the media representations of them we consume as well as our own individual imaginings of what the spaces we inhabit mean to us. If there's a unifying element to her discussions of ethnic media, the urban poor, street art, bohemian hipsters, protest movements and rioters, then it would be an intentional critique of neoliberal capitalism and an idealised celebration of anything that resembles counterhegemonic resistance to it.

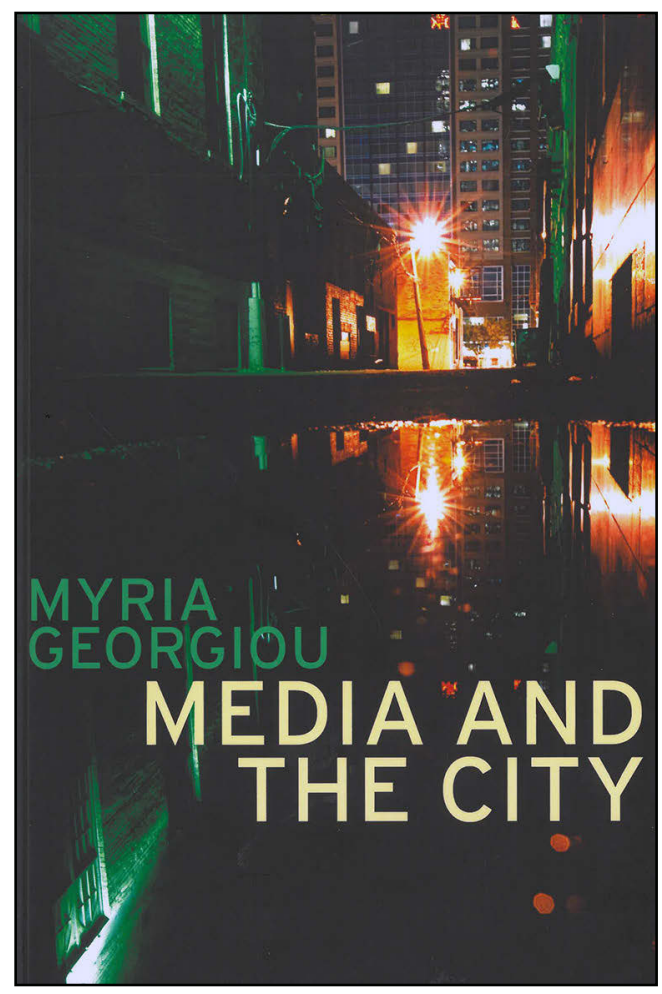

Georgiou does convincingly convey the tensions inherent in any environment where significant disparities between affluence and influence exist; but in prose so dense that as we approach the 20th anniversary of the Sokal hoax it might be timely to reflect on what those who use critical cultural approaches have learned since.

This reviewer would be the first to admit his cognitive abilities might not be up to following the book's sophisticated arguments. Yet any work which so quickly dismisses the role and relevance of one of the world's premiere financial districts while lauding the alternative middle-class lifestyles parodied in Portlandia, perhaps deserves to be questioned.-Steve Ellmers is a Unitec tutor. 